\title{
Rethinking the definition of episodic memory
}

\author{
Christopher R. Madan \\ School of Psychology \\ University of Nottingham
}

\begin{abstract}
The definition of episodic memory, as proposed by Tulving, includes a requirement of conscious recall. As we are unable to assess this aspect of memory in non-human animals, many researchers have referred to demonstrations of what would otherwise be considered episodic memory as "episodic-like memory." Here the definition of episodic memory is re-considered based on objective criteria. While the primary focus of this re-evaluation is based on work with non-human animals, considerations are also drawn from converging evidence from cognitive psychology, neuropsychology, and cognitive neuroscience. Implications of this rethinking are discussed, as well as considerations of familiarity, indirect measures of memory, and generally what should be viewed as necessary for episodic memory. This perspective is intended to begin an iterative process within the field to redefine the meaning of episodic memory and to ultimately establish a consensus view.
\end{abstract}

Keywords: episodic memory, non-human animals, recollection, hippocampus

Public Significance Statement

Being able to remember our past experiences, such as the specific event details from a recent dinner with friends or when you moved to a new city, rely on episodic memory. Based on the conventional definition proposed by Endel Tulving decades ago, only humans have episodic memory and it is inexplicably intertwined with consciousness and introspection. Here I suggest we rethink this definition based on criteria that can be externally verified and objectively evaluated.

\section{Introduction}

Most of us can think back to the previous week (e.g., a recent dinner with friends) and events of importance (e.g., moving to a new place) without much difficulty. Can non-human animals engage in similar behaviour? By the current definition of episodic memory, this inability to peer into the introspective behaviours of nonhuman animals means we can only ascribe evidence of 'episodic-like' memory to non-human animals. This approach seems overly limited and anthropocentric. Here I suggest that we shift toward more objective criteria for defining episodic memory that do not rely on introspection or necessitate conscious recollection. The implications of this rethinking are discussed, as well

Corresponding author:

Christopher R. Madan

School of Psychology, University of Nottingham

Nottingham, NG7 2RD, United Kingdom

christopher.madan@nottingham.ac.uk as considerations of familiarity, indirect measures of memory, and generally what should be viewed as necessary for episodic memory. Episodic memory is studied in a variety of subfields within psychology, including cognitive psychology, neuropsychology, and cognitive neuroscience, in addition to comparative psychology. In this article, I draw from converging evidence from all of these subfields to suggest a path forward that may be consistently and broadly used. By adopting a new definition that can be externally verified, objectively evaluated, and less reliant on selfreport, episodic memory can be more consistently assessed across a variety of subfields. This perspective is intended to begin an iterative process within the field to redefine the meaning of episodic memory and to ultimately establish a consensus view.

The current definition of episodic memory, as described in Tulving $(2002$, p.5), includes a rich characterisation of the concept:

Episodic memory is a recently evolved, late-developing, and early-deteriorating 
past-oriented memory system, more vulnerable than other memory systems to neuronal dysfunction, and probably unique to humans. It makes possible mental time travel through subjective time, from the present to the past, thus allowing one to re-experience, through autonoetic awareness, one's own previous experiences. Its operations require, but go beyond, the semantic memory system. Retrieving information from episodic memory (remembering or conscious recollection) is contingent on the establishment of a special mental set, dubbed episodic "retrieval mode." Episodic memory is subserved by a widely distributed network of cortical and subcortical brain regions that overlaps with but also extends beyond the networks subserving other memory systems. The essence of episodic memory lies in the conjunction of three concepts-self, autonoetic awareness, and subjectively sensed time.

Critically, Tulving drew a direct and unambiguous correspondence between systems of memory (episodic, semantic, and procedural) and the involvement of consciousness, with episodic memory corresponding to autonoetic (self-knowing) consciousness. Based on this definition, often it is suggested that animals have "episodic-like memory," rather than episodic memory itself, as it cannot be known if an animal has consciously recalled the information. Moreover, Tulving (2002) clearly states that episodic memory as "probably unique to humans" and this definition as a whole sets up the definition of episodic memory such that it only could be available to humans, without saying that explicitly; some others have taken similar stances with episodic memory (and mental time travel) being reserved to humans (Roberts, 2002; Suddendorf \& Busby, 2003; Suddendorf \& Corballis, 2007; Murray et al., 2017). Even with regards to episodic memory in (human) children, some memory researchers take a relatively strict view that may be limited by language comprehension-thus attributing a relatively later age for the onset of episodic memory abilities (e.g., Roberts, 2002; Friedman, 1991), while others consider a more minimal definition of re-experiencing (e.g., Clayton \& Russell, 2009; Bauer \& Leventon, 2012). Here I suggest that Tulving's definition of episodic memory is overly anthropocentric and that we should drop the use of "episodic-like" memory. To implement this modification, we need to re-evaluate our definition of episodic memory to be independent of conscious recall and shift to criteria that can be externally verified and objec- tively evaluated, rather than rely on introspective reports. Thus, the approach proposed here is to disentangle consciousness from the definition of episodic memory and adopt methods that are more objective (e.g., source-memory test vs. remember/know procedure), as well as turn to neuropsychological dissociation findings, to remove this dependency. This is not necessarily to suggest that episodic memory and consciousness are not related, but rather to allow for separations in their definitions that can be individually evaluated independently and rely less on anthropocentric thinking. Admittedly, Tulving (2005) makes a similar argument, but in the opposite direction-suggesting that it is anthropocentric to think that animals' memory works similarly to our own. While I agree with the premise of this perspective, my goal is to move further towards objective tests of memory, in contrast to Tulving's use of introspective judgments.

When first proposed, Tulving (1972, p.384) did not have a strong view of episodic and semantic memory as being distinctly different: "I will refer to both kinds of memory as as two stores, or as two systems, but I do this primarily for the convenience of communication, rather than as an expression of any profound belief about structural or functional separation of the two." Later, Tulving (1983) strengthened this distinction by suggesting that these two memory systems differed in their biological basis. In subsequent decades, Tulving shifted his view further-Tulving (2002, p.5) stated: "Episodic memory is a recently evolved, late-developing, and early-deteriorating pastoriented memory system, more vulnerable than other memory systems to neuronal dysfunction, and probably unique to humans." Importantly, Tulving (2002) does acknowledge that his perspective on episodic memory as a concept has changed drastically over the thirty years since his initial 1972 work, so I consider the 2002 perspective as the primary definition of episodic memory. (For a more exhaustive overview of how the concept of episodic memory has developed over the decades, see Tulving, 2002; for a brief anecdotal description of the very beginnings of the term episodic memory, see Tulving, 2016.)

To reiterate, my goal here is not to suggest that there is no distinction or continuum between episodic and semantic memory, but rather to re-evaluate the definition of episodic memory and our current understanding of memory in non-human animals, and to consider how we can test for episodic memory more objectively. Tulving (2002) himself comments that some other well-known memory researchers do not agree with his strong distinction between episodic and semantic memory, providing us with insight that even 
with a contemporary understanding of the literature, his criteria for the specific distinction between memory systems was not without issues. While others over the years have also considered these two systems of memory to be quite distinct, as has been true of many other topics in cognitive psychology, recent evidence has demonstrated that episodic and semantic memory share many attributes, lying more along a continuum, and being interdependent systems (Craik, 2000, 2020; Greenberg \& Verfaellie, 2010; Saive et al., 2015; Renoult et al., 2019).

\section{Disentangling episodic memory from consciousness}

Returning to Tulving, from when he first made the connection between episodic memory and consciousness (1985, p.1):

\begin{abstract}
Nowhere is the benign neglect of consciousness more conspicuous than in the study of human memory. One can read article after article on memory, or consult book after book, without encountering the term "consciousness." Such a state of affairs must be regarded as rather curious. One might think that memory should have something to do with remembering, and remembering is a conscious experience. To remember an event means to be consciously aware now of something that happened on an earlier occasion. Nevertheless, through most of its history, including the current heyday of cognitive psychology, the psychological study of memory has largely proceeded without reference to the existence of conscious awareness in remembering.
\end{abstract}

Is this dependency on consciousness necessary? Perhaps it is functionally, but-can we test for episodic memory independently of consciousness? This requirement of conscious recall inherently cannot be evidenced in non-human animals (Clayton et al., 2000), leading researchers to refer to what otherwise would be considered as episodic memory in humans as "episodic-like memory" in animals. Moreover, socalled episodic-like memory has been observed in a large range of species, including non-human primates (Schwartz \& Evans, 2001; Schwartz et al., 2005; Menzel, 2005; Hoffman et al., 2009; Basile \& Hampton, 2011; Fagot \& Cook, 2006), a variety of avian species (Clayton \& Dickinson, 1998; Clayton et al., 2001; Zentall et al., 2001; Cook et al., 2005; Fagot \& Cook, 2006; Skov-Rackette et al., 2006; Dally et al., 2006; Zentall et al., 2008; Feeney et al., 2009; González-Gómez et al., 2011; Qadri et al., 2018), but also dogs (Fugazza et al., 2016; Sluka et al., 2018; Lo \& Roberts, 2020), horses (Hanggi \& Ingersoll, 2009; Valenchon et al., 2013), dolphins (Mercado et al., 1999), cuttlefish (JozetAlves et al., 2013), rodents (Babb \& Crystal, 2005; Zhou \& Crystal, 2009; Davis et al., 2013; Panoz-Brown et al., 2016, 2018), and even insects (Pahl et al., 2007; Perry et al., 2017). While it is possible that episodic memory is a cognitive function that is uniquely humanit is more plausible that current distinctions between episodic and episodic-like memory are so similar that it would be more useful to view them both as episodic memory. Moreover, current evidence of episodic-like memory has been used as supportive evidence for the notion of animal consciousness (Griffin \& Speck, 2004)further complicating the usefulness of the current definitions of episodic and episodic-like memory. Recent behavioural work with non-humans, as well as plants, has further demonstrated that evaluating the presence of consciousness is a complicated topic (Segundo-Ortin \& Calvo, 2019; Taiz et al., 2019; Pagán, 2019; Carruthers et al., 2019). Indeed, without turning to self-report, it is difficult to measure consciousness in humans, as the definition of consciousness itself is nebulous at best.

While dissociating episodic memory from consciousness, it is useful to be reminded that there are terms that may benefit from increased use in the literature, particularly in more precisely characterising the link between episodic memory and consciousness. The act of conscious recollection has been termed "ecphory" (Semon, 1921; also see Schacter et al., 1978, and Schacter, 2001), though this term is often falsely attributed to Tulving (e.g., Daselaar et al., 2001; Kinoshita, 2002; Markowitsch et al., 1999, 2003; Kim, 2013). I do not dispute that ecphory is a cognitive process that humans can engage in; but here I suggest that conscious recall, ecphory, should not be considered as a requirement for demonstrating episodic memory ability, and consider that it is unclear whether nonhuman animals can engage in ecphory. In relation to the Tulving (2002) definition of episodic memory, an alternative is to consider that studies provide evidence of episodic memory either with or without ecphory.

\section{Defining boundaries of episodic memory}

Apart from removing the requirement of conscious recollection, a more nuanced discussion of what should be considered as episodic memory is also warranted. An independent, but largely convergent approach may be to make this discrimination based on neurobiological, functional specialization and consider episodic memory to be hippocampal dependent. This approach has the additional benefit of being atheoretical, directly testable, and ensures that cognitive theory is linked 
to biology. As such, memory for items without additional contextual information, which can be remembered by amnesic patients (with hippocampal damage) in item-recognition tests (e.g., Mayes et al., 2002; Holdstock et al., 2002, 2005), would not qualify as a sufficient test of episodic memory. This view is congruent with Tulving (2002), and corrects an over generalization made by Tulving (1972). Nonetheless, tests of memory involving contextual information-e.g., source, association, or order-would here be considered as assessing episodic memory. Additionally, tests of memory specificity, such as the mnemonic similarity task (Yassa \& Stark, 2011; Stark et al., 2013, 2019), where recognition is tested for old items as well as similar items would also be considered a test of episodic memory (i.e., if episodic memory includes a 'which' component to differentiate two items that are very similar). Considerations of the experimental procedure, and potentially if the task can be accomplished with a hippocampal lesion, would sometimes be needed to distinguish between a test of contextual memory versus, for instance, conditioned place preference. However, this is not intended to be a one-to-one mapping, while I am suggesting that episodic memory requires the hippocampus, this does not mean that the hippocampus is limited to only being involved in episodic memory or that any task that requires the hippocampus is bydefinition also considered an episodic memory task.

This perspective of examining contextual memory, without regard to interpreting the autonoetic properties (which is unmeasurable and introspective), is consistent with the views of many non-human memory researchers (e.g., Clayton \& Dickinson, 1998; Babb \& Crystal, 2005; Skov-Rackette et al., 2006; Pahl et al., 2007; Feeney et al., 2009; Hoffman et al., 2009; Davis et al., 2013; Lo \& Roberts, 2020). More directly, hippocampal volume has been linked to memory capacity both within and across non-human species (e.g., Sherry et al., 1989; Krebs et al., 1989; Clayton, 1995; Hampton \& Shettleworth, 1996; Volman et al., 1997; Lee et al., 1998; Cnotka et al., 2008). While there is some convergent evidence of regional hippocampal volume correlating with memory capacity in humans (Maguire et al., 2000, 2006), this relationship may not be present as a continuous measure (see Weisberg et al., 2019). Regardless of inter-individual differences in memory capacity, the notion that memory for contextual information (what, where, when, which) is an important aspect of episodic memory and requires the hippocampus is in line with previous conceptions of episodic memory (Tulving, 1983, 1984). This view is also convergent with Clayton et al. (2000), albeit with a different rationale; though this was no longer sufficient af- ter the addition of the requirement of autonoetic experiences by Tulving $(1985,2002)$. Thus, for reasons of both parsimony and objective measurement, here I propose a consistent view also be taken for human memory research-and adopted as the formal definition of episodic memory. I consider the hippocampus as being central to episodic memory based on it's consistent involvement in recollection, memory for contextual information, and mental time travel. Admittedly, the hippocampus is not a unitary neurobiological structure (e.g., see Small, 2002; Strange et al., 2014; Hrybouski et al., 2019), but I will not be differentiating between the hippocampal subfields or long-axis specialisation here.

\section{Reconciling the definition of episodic memory with the broader literature}

If we are to consider a less restrictive definition of episodic memory, we must, of course, also consider the broader implications.

\section{Is familiarity a type of episodic memory?}

While we cannot ask non-human animals to make a subjective judgments of memory recollection versus familiarity-we can, and do, with humans. One of the goals of the present work is to make considerations of the definition of episodic memory serve both. Briefly, when testing memory for individual items with humans, sometimes the participants are asked to evaluate if they can recollect qualitative details of an experience (i.e., remember) or merely have a sense of familiarity without these richer details (i.e., knowing). In these tasks, participants are given the option of responding remember, know, or new for each recognition item (Tulving, 1985; Java et al., 1997; Gardiner, 2001; Dudukovic \& Knowlton, 2006; Migo et al., 2012). To date, this approach to studying memory has been used in hundreds of studies.

Providing strong support for the distinction between recollection and familiarity, patients with hippocampal damage show selective impairments to recollection and associative processing (e.g., Verfaellie et al., 2000; Yonelinas, 2001; Holdstock et al., 2002; Giovanello et al., 2003; Mayes et al., 2004; Turriziani et al., 2004; Aggleton et al., 2005; Brandt et al., 2009; Vann et al., 2009). Convergently, neuroimaging studies have demonstrated greater hippocampal activation for recollection-related responses than familiarity responses (e.g., Eldridge et al., 2000; Davachi et al., 2003; Ranganath et al., 2003; Cohn et al., 2009; Mayes et al., 2019). Providing evidence of a possible double dissociation, Brandt et al. (2016) report on experiments with patient M.R., who has an entorhinal cortex lesion that resulted in impaired familiarity, but intact recollection. 
Despite this compelling evidence, it is also important to acknowledge that lesions to other brain regions, such as in the case of semantic dementia, can also have influences on recollection and familiarity (e.g., Hodges \& Graham, 2001). Recollection responses have also been associated with successful retrieval of other contextual information (e.g., what, where, when, which) (e.g., Saive et al., 2015); when a simple old/new recognition task is used, recollection is often considered based on source-memory performance (e.g., Davachi et al., 2003; Ranganath et al., 2003).

Given the inherent introspective nature of asking a human participant to discriminate between "remember" and "know" responses and then mapping these to processes corresponding to recollection and familiarity, we become too reliant on self-report judgments rather than distinguishing between differences in memory representations or mechanisms. Indeed, it can be argued that greater consideration is needed to define what these terms mean in reference to cognitive representations and neurocomputational operations-see Cowell et al. (2019) for a more nuanced discussion. Moreover, subjective responses are vulnerable to biases; for example, there are instances where an amnesic patient can recognise an item as well as a healthy control participant, but generally has more deficits. Here the patient may be unlikely to respond "remember" due to their general memory deficits, and this problem may also apply to other cohort differences in betweengroups analyses (see Madan \& Singhal, 2013 paper for examples in another domain of cognitive psychology).

If familiarity is not considered sufficient for episodic memory, an open question is to consider what it is instead. While familiarity is included as a type of episodic memory by some (Eldridge et al., 2000; Yonelinas, 2001), others have classified it as "non-episodic" (Dudukovic \& Knowlton, 2006; Palombo et al., 2015) or as a type of semantic memory (Yonelinas, 2002; Yonelinas et al., 2002; Zentall et al., 2008; Bartsch et al., 2011)-including Tulving in the past (Tulving, 1985). Some have also considered familiarity as being influenced by a mixture of both episodic and semantic memory (as well as other processes) (e.g., Jacoby \& Dallas, 1981; Johnston et al., 1991; Whittlesea, 1993; Dewhurst \& Hitch, 1997; Schacter et al., 1999; Budson et al., 2006; Migo et al., 2012; Wang et al., 2018), and this is the position most strongly supported by current evidence. This mixture view of familiarity could also be considered as a combination of both general (semantic) item familiarity (e.g., Gilhooly \& Logie, 1980) and episodic memory traces, similarly to the distinction between primary and secondary distinctiveness (Schmidt, 1991). Primary distinctiveness is based on being distinct in salience/congruity within a local, episodic context (e.g., akin to an oddball or vonRestorff paradigm); secondary distinctiveness is instead in distinct relation to general knowledge or experiences, thus corresponding to semantic memory. One approach that has been demonstrated to be successful with both humans and non-humans in decreasing the influence of familiarity in recognition procedures is to ensure that all items have been pre-familiarised such that the lures are not entirely 'new' to the experimental task and to match lures as closely as possible to the old items (e.g., Panoz-Brown et al., 2016; Brady \& Hampton, 2018; Madan et al., 2017).

Given this boundary criterion of familiarity being insufficient for qualifying as episodic memory, what remains and follows from dual-process theory is recollection. More broadly, this can be considered as memory for items along with contextual information, such as location, time, value, or any of a myriad of other attributes that can be considered evidence of remembered source information. Though few studies have done so, source memory can be tested in non-human animals (e.g., Crystal et al., 2013).

\section{Which memory measures evaluate episodic mem- ory?}

Not all memory measures are necessarily dependent on episodic memory. As already discussed, old/new recognition can be relatively spared with hippocampal damage (e.g., Mayes et al., 2002; Holdstock et al., 2002, 2005). In contrast, performance was highly impaired in recall tests. This distinction between recognition and a recall/generation process can be critical to the necessity of hippocampal engagement. With humans, it can sometimes be difficult to implement a recall test due to its requisite open-ended nature, rather than a matchto-sample recognition procedure, in some experimental settings, e.g., in an MRI scanner. Nonetheless, the use of modified procedures such as a hybrid metamemorycued recall (e.g., Caplan \& Madan, 2016; Madan et al., 2017) or item-recognition-cued recall (e.g., Madan et al., 2020) procedure can be used to increase sensitivity to hippocampal engagement.

Another important distinction in memory test procedures, with humans, is the use of direct or indirect measures (Johnson \& Hasher, 1987; Richardson-Klavehn \& Bjork, 1988). Briefly, direct memory measures ask the participant directly to make memory-related responses, such as old/new recognition, free recall, associative recognition, or cued recall. Indirect measures, in contrast, are ones where memory may 'spill-over' and influence the participants' response, but is not directly asked for, such as lexical decision, word-stem comple- 
tion, or preference ratings. (Note, many would instead refer to these as explicit vs. implicit tests of memory, but that involves an inference about the nature of memory systems themselves, rather than being a more objective characterisation of the task design.) With some consideration, both recognition and recall can be evaluated using both direct and indirect memory measures (see Jacoby \& Hollingshead, 1990).

A key difference between direct and indirect measures of memory is the necessity of conscious recollection (i.e., ecphory) (Johnson \& Hasher, 1987). Based on Tulving's (2002) definition of episodic memory, a direst test of memory that is associated with a successful memory must engage ecphory, whereas a forgotten memory would not involve ecphory. Tulving's definition would further suggest that indirect measures of memory cannot be based on episodic memory. However, if one were trained to associate individual words with reward values and then be presented with these words again in a lexical decision test (as in Madan et al., 2012; Chakravarty et al., 2019), an influence of reward value on lexical decision response time is one based on episodic memory, not a change in the word's semantic meaning. Is this judgement on the reliance of itemvalue associations on episodic memory contingent on whether the participant is or is not able to explicitly recall the value of an item in a value-judgement task? This is one instance of where the current perspective's boundaries for episodic memory still remains hazy. Further complicating matters, some memory tasks can be accomplished with a mixture of different strategies, where one is likely hippocampal dependent and another relies on a different memory system (e.g., basal ganglia) (e.g., Iaria et al., 2003; Dahmani \& Bohbot, 2015).

Tests of episodic(-like) memory in animals are often recognition. Moreover, given these definitions of direct and indirect tests-all (or at least, most) tests of memory in animals would be indirect measures of memory, and are rather tests of preference. Specifically, animals cannot be instructed and memory tests are effectively reliant on past reward histories guiding choice in combination with familiarity/novelty signals. However, some studies have used more complex procedures to distinguish responses based on item-source/context associations from those that would be based on merely preference due to familiarity/recency (Crystal et al., 2013; Panoz-Brown et al., 2016).

\section{Difficulties in testing memory in non-human ani- mals}

When studying memory in non-human animals, it can be difficult to separate a test of memory from a test of choice or preference; for instance, if the study involves associating items with reward outcomes (e.g. Madan \& Spetch, 2012; Madan et al., 2014, 2019; Ludvig et al., 2014). As a result, some tasks that are relatively straightforward to conduct in humans cannot be translated to non-human animals.

More broadly, Tulving (2002) expressed that there was no evidence that non-human animals can engage in mental time travel. While this may have seemed more clear-cut at the time, research in the past two decades has provided evidence of mental time travel in non-human animals. For instance, Clayton and Dickinson (1998) conducted a well-designed study where scrub jays cached perishable food (wax-moth larvae) and non-perishable food (peanuts). When allowed to retrieve the stored food after a short delay, they preferred the fresh larvae. When recovering food after a long interval, the jays quickly learned to avoid the now-decayed larvae and to instead recover the cached peanuts. This study provides relatively clear evidence that the jays not only remembered where they had cached food, but also which food was cached at each location and when it has been cached-allowing the jay to infer the fresh or decayed state in the case of the perishable larvae.

Providing a more direct example of mental time travel, we can also turn to the behaviour labeled 'vicarious trial-and-error learning.' Here, researchers had observed that when navigating complex $\mathrm{T}$ mazes, rats would sometimes stop at the choicepoint/intersections and look at either potential pathway, seemingly to deliberately consider the potential outcomes of the decision (Muenzinger, 1938; Tolman, $1939,1948)$. More recent work has explored this behaviour further, more explicitly linking it to prospective hippocampal firing rate activity (sometimes referred to as "preplay") and mental time travel (Redish, 2016; Dragoi \& Tonegawa, 2013; Ólafsdóttir et al., 2015; de la Prida, 2020; Kay et al., 2020). While it is difficult or even impossible to gain true insight into the introspective process that this behaviour corresponds to, it is plausible that it corresponds to a conscious recollection experience. Regardless, it must be conceded that this procedure has provided more objective evidence of episodic memory than the subjective criterion that is currently used with humans based on self-report in a remember/know procedure.

Despite there being some evidence of mental time travel in non-human animals, this ability may not be necessary to demonstrate memory for contextual information (i.e., what, when, where, which) in these tasks in some or all other species. That is, even when mental time travel is possible, it may not be the same 'strategy' 
used by animals when presented with a task in which a human would engage in mental time travel. While this makes interpreting behavioural findings more complex, it also provides further motivation for the development of objective, non-introspective, measures of episodic memory.

\section{A new definition of episodic memory}

To provide a summary of the suggestions made in this article, here I propose a new definition of episodic memory:

Episodic memory is the remembrance of one's own previous experiences and can be done by both human and non-human animals. Episodic memory is supported by a distributed network of cortical and subcortical brain regions, but requires the involvement of the hippocampus-unlike other memory systems. Mental time travel, the re-experiencing or imagining of a sequence of events, is dependent on episodic memory. Familiarity may involve episodic memory but is not a type of episodic memory, as familiarity is also dependent on other memory processes.

Additionally, this new definition does not require conscious recollection and there is no distinction between episodic and episodic-like memory. When possible, self-report distinctions between memory processes should be avoided (e.g., remember/know procedures) and should be instead tested using source-memory or item-strength (such as confidence ratings) procedures.

\section{Conclusion}

While there is a need for consistent definitions in the literature, there also is a need to periodically re-evaluate these definitions as a facet of moving the field forward. The evidence presented here is suggestive of a less restrictive and more parsimonious view of episodic memory that can be more objectively evaluated empirically. Several takeaway messages are discussed in this article, not the least of which is that researchers of human memory may underestimate the extent of memory phenomena that can also be found in non-human animals, for instance, false memories (Millin \& Riccio, 2019). The perspective presented here can be refined further, but hopefully represents a notable step forward in how we understand and assess episodic memory.

\section{Acknowledgments}

I would like to thank Daniela Palombo for insightful discussions that helped refine the ideas presented in this manuscript.
References

Aggleton, J. P., Vann, S. D., Denby, C., Dix, S., Mayes, A. R., Roberts, N., \& Yonelinas, A. P. (2005). Sparing of the familiarity component of recognition memory in a patient with hippocampal pathology. Neuropsychologia, 43, 1810-1823. doi: 10.1016/j.neuropsychologia.2005.01.019

Babb, S. J., \& Crystal, J. D. (2005). Discrimination of what, when, and where: Implications for episodic-like memory in rats. Learning and Motivation, 36, 177-189. doi: 10.1016/j.lmot.2005.02.009

Bartsch, T., Dohring, J., Rohr, A., Jansen, O., \& Deuschl, G. (2011). CA1 neurons in the human hippocampus are critical for autobiographical memory, mental time travel, and autonoetic consciousness. Proceedings of the National Academy of Sciences USA, 108, 17562-17567. doi: $10.1073 /$ pnas. 1110266108

Basile, B. M., \& Hampton, R. R. (2011). Monkeys recall and reproduce simple shapes from memory. Current Biology, 21, 774-778. doi: 10.1016/j.cub.2011.03.044

Bauer, P. J., \& Leventon, J. S. (2012). Memory for one-time experiences in the second year of life: Implications for the status of episodic memory. Infancy, 18, 755-781. doi: 10.1111/infa.12005

Brady, R. J., \& Hampton, R. R. (2018). Nonverbal working memory for novel images in rhesus monkeys. Current Biology, 28, 3903-3910. doi: 10.1016/j.cub.2018.10.025

Brandt, K. R., Eysenck, M. W., Nielsen, M. K., \& von Oertzen, T. J. (2016). Selective lesion to the entorhinal cortex leads to an impairment in familiarity but not recollection. Brain and Cognition, 104, 82-92. doi: 10.1016/j.bandc.2016.02.005

Brandt, K. R., Gardiner, J. M., Vargha-Khadem, F., Baddeley, A. D., \& Mishkin, M. (2009). Impairment of recollection but not familiarity in a case of developmental amnesia. Neurocase, 15, 60-65. doi: 10.1080/13554790802613025

Budson, A. E., Todman, R. W., Chong, H., Adams, E. H., Kensinger, E. A., Krangel, T. S., \& Wright, C. I. (2006). False recognition of emotional word lists in aging and alzheimer disease. Cognitive and Behavioral Neurology, 19, 71-78. doi: 10.1097/01.wnn.0000213905.49525.d0

Caplan, J. B., \& Madan, C. R. (2016). Word imageability enhances association-memory by increasing hippocampal engagement. Journal of Cognitive Neuroscience, 28, 15221538. doi: 10.1162/jocn_a_00992

Carruthers, G., Carls-Diamante, S., Huang, L., Rosen, M., \& Schier, E. (2019). How to operationalise consciousness. Australian Journal of Psychology, 71, 390-410. doi: 10.1111/ajpy.12264

Chakravarty, S., Fujiwara, E., Madan, C. R., Tomlinson, S. E., Ober, I., \& Caplan, J. B. (2019). Value bias of verbal memory. Journal of Memory and Language, 107, 25-39. doi: 10.1016/j.jml.2019.03.005

Clayton, N. S. (1995). Development of memory and the hippocampus: comparison of food-storing and nonstoring birds on a one-trial associative memory task. The Journal of Neuroscience, 15, 2796-2807. doi: 10.1523/jneurosci.15-0402796.1995 
Clayton, N. S., \& Dickinson, A. (1998). Episodic-like memory during cache recovery by scrub jays. Nature, 395, 272-274. doi: $10.1038 / 26216$

Clayton, N. S., Griffiths, D. P., \& Dickinson, A. (2000). Declarative and episodic-like memory in animals: Personal musings of a scrub jay. In C. Heyes \& L. Huber (Eds.), The evolution of cognition (pp. 273-288). MIT Press.

Clayton, N. S., \& Russell, J. (2009). Looking for episodic memory in animals and young children: Prospects for a new minimalism. Neuropsychologia, 47, 2330-2340. doi: 10.1016/j.neuropsychologia.2008.10.011

Clayton, N. S., Yu, K. S., \& Dickinson, A. (2001). Scrub jays (Aphelocoma coerulescens) form integrated memories of the multiple features of caching episodes. Journal of Experimental Psychology: Animal Behavior Processes, 27, 17-29. doi: 10.1037/0097-7403.27.1.17

Cnotka, J., Möhle, M., \& Rehkämper, G. (2008). Navigational experience affects hippocampus size in homing pigeons. Brain, Behavior and Evolution, 72, 233-238. doi: 10.1159/000165102

Cohn, M., Moscovitch, M., Lahat, A., \& McAndrews, M. P. (2009). Recollection versus strength as the primary determinant of hippocampal engagement at retrieval. Proceedings of the National Academy of Sciences USA, 106, 2245122455. doi: 10.1073/pnas.0908651106

Cook, R. G., Levison, D. G., Gillett, S. R., \& Blaisdell, A. P. (2005). Capacity and limits of associative memory in pigeons. Psychonomic Bulletin \& Review, 12, 350-358. doi: 10.3758/bf03196384

Cowell, R. A., Barense, M. D., \& Sadil, P. S. (2019). A roadmap for understanding memory: Decomposing cognitive processes into operations and representations. eNeuro, 6, 0122-19.2019. doi: 10.1523/eneuro.0122-19.2019

Craik, F. I. M. (2000). Age-related changes in human memory. In D. C. Park \& N. Schwarz (Eds.), Cognitive aging: A primer (pp. 75-92). Psychology Press.

Craik, F. I. M. (2020). Remembering: An activity of mind and brain. Annual Review of Psychology, 71. doi: 10.1146/annurev-psych-010419-051027

Crystal, J. D., Alford, W. T., Zhou, W., \& Hohmann, A. G. (2013). Source memory in the rat. Current Biology, 23, 387391. doi: 10.1016/j.cub.2013.01.023

Dahmani, L., \& Bohbot, V. D. (2015). Dissociable contributions of the prefrontal cortex to hippocampus- and caudate nucleus-dependent virtual navigation strategies. Neurobiology of Learning and Memory, 117, 42-50. doi: 10.1016/j.nlm.2014.07.002

Dally, J. M., Emery, N. J., \& Clayton, N. S. (2006). Foodcaching western scrub-jays keep track of who was watching when. Science, 312, 1662-1665. doi: 10.1126/science.1126539

Daselaar, S. M., Rombouts, S. A. R. B., Veltman, D. J., Raaijmakers, J. G. W., Lazeron, R. H. C., \& Jonker, C. (2001). Parahippocampal activation during successful recognition of words: A self-paced event-related fMRI study. NeuroImage, 13, 1113-1120. doi: 10.1006/nimg.2001.0758

Davachi, L., Mitchell, J. P., \& Wagner, A. D. (2003). Multiple routes to memory: Distinct medial temporal lobe pro- cesses build item and source memories. Proceedings of the National Academy of Sciences USA, 100, 2157-2162. doi: $10.1073 /$ pnas.0337195100

Davis, K. E., Easton, A., Eacott, M. J., \& Gigg, J. (2013). Episodic-like memory for what-where-which occasion is selectively impaired in the $3 \times \mathrm{TgAD}$ mouse model of Alzheimer's disease. Journal of Alzheimer's Disease, 33, 681-698. doi: 10.3233/JAD-2012-121543

de la Prida, L. M. (2020). Potential factors influencing replay across CA1 during sharp-wave ripples. Philosophical Transactions of the Royal Society B: Biological Sciences, 375, 20190236. doi: $10.1098 /$ rstb.2019.0236

Dewhurst, S. A., \& Hitch, G. J. (1997). Illusions of familiarity caused by cohort activation. Psychonomic Bulletin $\mathcal{E}$ Review, 4, 566-571. doi: 10.3758/bf03214350

Dragoi, G., \& Tonegawa, S. (2013). Distinct preplay of multiple novel spatial experiences in the rat. Proceedings of the National Academy of Sciences USA, 110, 9100-9105. doi: 10.1073 /pnas. 1306031110

Dudukovic, N. M., \& Knowlton, B. J. (2006). Remember/know judgments and retrieval of contextual details. Acta Psychologica, 122, 160-173. doi: 10.1016/j.actpsy.2005.11.002

Eldridge, L. L., Knowlton, B. J., Furmanski, C. S., Bookheimer, S. Y., \& Engel, S. A. (2000). Remembering episodes: a selective role for the hippocampus during retrieval. Nature Neuroscience, 3, 1149-1152. doi: 10.1038/80671

Fagot, J., \& Cook, R. G. (2006). Evidence for large long-term memory capacities in baboons and pigeons and its implications for learning and the evolution of cognition. Proceedings of the National Academy of Sciences USA, 103, 1756417567. doi: $10.1073 /$ pnas.0605184103

Feeney, M. C., Roberts, W. A., \& Sherry, D. F. (2009). Memory for what, where, and when in the black-capped chickadee (Poecile atricapillus). Animal Cognition, 12, 767-777. doi: 10.1007/s10071-009-0236-x

Friedman, W. J. (1991). The development of children's memory for the time of past events. Child Development, 62, 139155. doi: $10.2307 / 1130710$

Fugazza, C., Pogány, Á., \& Miklósi, Á. (2016). Recall of others' actions after incidental encoding reveals episodiclike memory in dogs. Current Biology, 26, 3209-3213. doi: 10.1016/j.cub.2016.09.057

Gardiner, J. M. (2001). Episodic memory and autonoetic consciousness: a first-person approach. Philosophical Transactions of the Royal Society of London. Series B: Biological Sciences, 356, 1351-1361. doi: 10.1098/rstb.2001.0955

Gilhooly, K. J., \& Logie, R. H. (1980). Age-of-acquisition, imagery, concreteness, familiarity, and ambiguity measures for 1, 944 words. Behavior Research Methods \& Instrumentation, 12, 395-427. doi: 10.3758/bf03201693

Giovanello, K. S., Verfaellie, M., \& Keane, M. M. (2003). Disproportionate deficit in associative recognition relative to item recognition in global amnesia. Cognitive, Affective, \& Behavioral Neuroscience, 3, 186-194. doi: 10.3758/cabn.3.3.186

González-Gómez, P. L., Bozinovic, F., \& Vásquez, R. A. (2011). Elements of episodic-like memory in free-living 
hummingbirds, energetic consequences. Animal Behaviour, 81, 1257-1262. doi: 10.1016/j.anbehav.2011.03.014

Greenberg, D. L., \& Verfaellie, M. (2010). Interdependence of episodic and semantic memory: Evidence from neuropsychology. Journal of the International Neuropsychological Society, 16, 748-753. doi: 10.1017/s1355617710000676

Griffin, D. R., \& Speck, G. B. (2004). New evidence of animal consciousness. Animal Cognition, 7, 5-18. doi: 10.1007/s10071-003-0203-x

Hampton, R. R., \& Shettleworth, S. J. (1996). Hippocampus and memory in a food-storing and in a nonstoring bird species. Behavioral Neuroscience, 110, 946-964. doi: 10.1037/0735-7044.110.5.946

Hanggi, E. B., \& Ingersoll, J. F. (2009). Long-term memory for categories and concepts in horses (Equus caballus). Animal Cognition, 12, 451-462. doi: 10.1007/s10071-008-0205-9

Hodges, J. R., \& Graham, K. S. (2001). Episodic memory: insights from semantic dementia. Philosophical Transactions of the Royal Society of London. Series B: Biological Sciences, 356, 1423-1434. doi: 10.1098/rstb.2001.0943

Hoffman, M. L., Beran, M. J., \& Washburn, D. A. (2009). Memory for 'what', 'where', and 'when' information in rhesus monkeys (Macaca mulatta). Journal of Experimental Psychology: Animal Behavior Processes, 35, 143-152. doi: $10.1037 / \mathrm{a} 0013295$

Holdstock, J. S., Mayes, A. R., Gong, Q. Y., Roberts, N., \& Kapur, N. (2005). Item recognition is less impaired than recall and associative recognition in a patient with selective hippocampal damage. Hippocampus, 15, 203-215. doi: 10.1002/hipo.20046

Holdstock, J. S., Mayes, A. R., Roberts, N., Cezayirli, E., Isaac, C. L., O'Reilly, R. C., \& Norman, K. A. (2002). Under what conditions is recognition spared relative to recall after selective hippocampal damage in humans? Hippocampus, 12, 341-351. doi: 10.1002/hipo.10011

Hrybouski, S., MacGillivray, M., Huang, Y., Madan, C. R., Carter, R., Seres, P., \& Malykhin, N. V. (2019). Involvement of hippocampal subfields and anteriorposterior subregions in encoding and retrieval of item, spatial, and associative memories: Longitudinal versus transverse axis. NeuroImage, 568-586. doi: 10.1016/j.neuroimage.2019.01.061

Iaria, G., Petrides, M., Dagher, A., Pike, B., \& Bohbot, V. D. (2003). Cognitive strategies dependent on the hippocampus and caudate nucleus in human navigation: Variability and change with practice. Journal of Neuroscience, 23, 59455952. doi: 10.1523/jneurosci.23-13-05945.2003

Jacoby, L. L., \& Dallas, M. (1981). On the relationship between autobiographical memory and perceptual learning. Journal of Experimental Psychology: General, 110, 306-340. doi: 10.1037/0096-3445.110.3.306

Jacoby, L. L., \& Hollingshead, A. (1990). Toward a generate/recognize model of performance on direct and indirect tests of memory. Journal of Memory and Language, 29, 433-454. doi: 10.1016/0749-596x(90)90065-8

Java, R. I., Gregg, V. H., \& Gardiner, J. M. (1997). What do people actually remember (and know) in 'remember/know' experiments? European Journal of Cognitive Psy- chology, 9, 187-197. doi: 10.1080/713752553

Johnson, M. K., \& Hasher, L. (1987). Human learning and memory. Annual Review of Psychology, 38, 631-668. doi: 10.1146/annurev.ps.38.020187.003215

Johnston, W. A., Hawley, K. J., \& Elliott, J. M. (1991). Contribution of perceptual fluency to recognition judgments. Journal of Experimental Psychology: Learning, Memory, and Cognition, 17, 210-223. doi: 10.1037/0278-7393.17.2.210

Jozet-Alves, C., Bertin, M., \& Clayton, N. S. (2013). Evidence of episodic-like memory in cuttlefish. Current Biology, 23, R1033-R1035. doi: 10.1016/j.cub.2013.10.021

Kay, K., Chung, J. E., Sosa, M., Schor, J. S., Karlsson, M. P., Larkin, M. C., ... Frank, L. M. (2020). Constant subsecond cycling between representations of possible futures in the hippocampus. Cell, 180, 552-567.e25. doi: 10.1016/j.cell.2020.01.014

Kim, H. (2013). Differential neural activity in the recognition of old versus new events: An activation likelihood estimation meta-analysis. Human Brain Mapping, 34, 814-836. doi: $10.1002 / \mathrm{hbm} .21474$

Kinoshita, S. (2002). Feeling of familiarity. In P. Chambres, M. Izaute, \& P.-J. Marescaux (Eds.), Metacognition (pp. 7990). Springer. doi: $10.1007 / 978-1-4615-1099-4 \_6$

Krebs, J. R., Sherry, D. F., Healy, S. D., Perry, V. H., \& Vaccarino, A. L. (1989). Hippocampal specialization of foodstoring birds. Proceedings of the National Academy of Sciences USA, 86, 1388-1392. doi: 10.1073/pnas.86.4.1388

Lee, D. W., Miyasato, L. E., \& Clayton, N. S. (1998). Relativeneurobiological bases of spatial learning in the natural environment: neurogenesis and growth in the avian and mammalian hippocampus. NeuroReport, 9, R15-R27.

Lo, K. H., \& Roberts, W. A. (2020). Dogs (Canis familiaris) use odor cues to show episodic-like memory for what, where, and when. Journal of Comparative Psychology. doi: 10.1037 /com0000174

Ludvig, E. A., Madan, C. R., Pisklak, J. M., \& Spetch, M. L. (2014). Reward context determines risky choice in pigeons and humans. Biology Letters, 10, 20140451-20140451. doi: 10.1098/rsbl.2014.0451

Madan, C. R., Fujiwara, E., Caplan, J. B., \& Sommer, T. (2017). Emotional arousal impairs association-memory: Roles of amygdala and hippocampus. NeuroImage, 156, 14-28. doi: 10.1016/j.neuroimage.2017.04.065

Madan, C. R., Fujiwara, E., Gerson, B. C., \& Caplan, J. B. (2012). High reward makes items easier to remember, but harder to bind to a new temporal context. Frontiers in Integrative Neuroscience, 6. doi: 10.3389/fnint.2012.00061

Madan, C. R., Knight, A. G., Kensinger, E. A., \& Steinmetz, K. R. M. (2020). Affect enhances objectbackground associations: evidence from behaviour and mathematical modelling. Cognition and Emotion. doi: 10.1080/02699931.2019.1710110

Madan, C. R., Ludvig, E. A., \& Spetch, M. L. (2014). Remembering the best and worst of times: Memories for extreme outcomes bias risky decisions. Psychonomic Bulletin $\mathcal{E}$ Review, 21, 629-636. doi: 10.3758/s13423-013-0542-9

Madan, C. R., Ludvig, E. A., \& Spetch, M. L. (2019). Comparative inspiration: From puzzles with pigeons to novel 
discoveries with humans in risky choice. Behavioural Processes, 160, 10-19. doi: 10.1016/j.beproc.2018.12.009

Madan, C. R., \& Singhal, A. (2013). Introducing TAMI: An objective test of ability in movement imagery. Journal of Motor Behavior, 45, 153-166. doi: 10.1080/00222895.2013.763764

Madan, C. R., \& Spetch, M. L. (2012). Is the enhancement of memory due to reward driven by value or salience? Acta Psychologica, 139, 343-349. doi: 10.1016/j.actpsy.2011.12.010

Maguire, E. A., Gadian, D. G., Johnsrude, I. S., Good, C. D., Ashburner, J., Frackowiak, R. S. J., \& Frith, C. D. (2000). Navigation-related structural change in the hippocampi of taxi drivers. Proceedings of the National Academy of Sciences USA, 97, 4398-4403. doi: 10.1073/pnas.070039597

Maguire, E. A., Woollett, K., \& Spiers, H. J. (2006). London taxi drivers and bus drivers: A structural MRI and neuropsychological analysis. Hippocampus, 16, 1091-1101. doi: 10.1002/hipo.20233

Markowitsch, H. J., Calabrese, P., Neufeld, H., Gehlen, W., \& Durwen, H. F. (1999). Retrograde amnesia for world knowledge and preserved memory for autobiographic events. a case report. Cortex, 35, 243-252. doi: 10.1016/s0010-9452(08)70797-4

Markowitsch, H. J., Vandekerckhove, M. P., Lanfermann, H., \& Russ, M. O. (2003). Engagement of lateral and medial prefrontal areas in the ecphory of sad and happy autobiographical memories. Cortex, 39, 643-665. doi: 10.1016/s0010-9452(08)70858-x

Mayes, A. R., Holdstock, J. S., Isaac, C., Montaldi, D., Grigor, J., Gummer, A., ... Norman, K. A. (2004). Associative recognition in a patient with selective hippocampal lesions and relatively normal item recognition. Hippocampus, 14, 763-784. doi: 10.1002/hipo.10211

Mayes, A. R., Holdstock, J. S., Isaac, C. L., Hunkin, N. M., \& Roberts, N. (2002). Relative sparing of item recognition memory in a patient with adult-onset damage limited to the hippocampus. Hippocampus, 12, 325-340. doi: 10.1002/hipo.1111

Mayes, A. R., Montaldi, D., Roper, A., Migo, E. M., Gholipour, T., \& Kafkas, A. (2019). Amount, not strength of recollection, drives hippocampal activity: A problem for apparent word familiarity-related hippocampal activation. Hippocampus, 29, 46-59. doi: 10.1002/hipo. 23031

Menzel, C. (2005). Progress in the study of chimpanzee recall and episodic memory. In H. S. Terrace \& J. Metcalfe (Eds.), The missing link in cognition: Origins of self-reflective consciousness (pp. 188-224). Oxford University Press. doi: 10.1093/acprof:oso/9780195161564.003.0008

Mercado, E., Uyeyama, R. K., Pack, A. A., \& Herman, L. M. (1999). Memory for action events in the bottlenosed dolphin. Animal Cognition, 2, 17-25. doi: $10.1007 / \mathrm{s} 100710050021$

Migo, E. M., Mayes, A. R., \& Montaldi, D. (2012). Measuring recollection and familiarity: Improving the remember/know procedure. Consciousness and Cognition, 21, 1435-1455. doi: 10.1016/j.concog.2012.04.014

Millin, P. M., \& Riccio, D. C. (2019). False memory in nonhuman animals. Learning $\mathcal{E}$ Memory, 26, 381-386. doi: 10.1101/lm.050054.119

Muenzinger, K. F. (1938). Vicarious trial and error at a point of choice: I. A general survey of its relation to learning efficiency. Journal of Genetic Psychology, 53, 75-86. doi: 10.1080/08856559.1938.10533799

Murray, E. A., Wise, S. P., \& Graham, K. S. (2017). The Evolution of Memory Systems. Oxford University Press. doi: 10.1093/acprof:oso/9780199686438.001.0001

Ólafsdóttir, H. F., Barry, C., Saleem, A. B., Hassabis, D., \& Spiers, H. J. (2015). Hippocampal place cells construct reward related sequences through unexplored space. eLife, 4. doi: 10.7554/elife.06063

Pagán, O. R. (2019). The brain: a concept in flux. Philosophical Transactions of the Royal Society B: Biological Sciences, 374, 20180383. doi: $10.1098 /$ rstb.2018.0383

Pahl, M., Zhu, H., Pix, W., Tautz, J., \& Zhang, S. (2007). Circadian timed episodic-like memory a bee knows what to do when, and also where. Journal of Experimental Biology, 210, 3559-3567. doi: 10.1242/jeb.005488

Palombo, D. J., Alain, C., Söderlund, H., Khuu, W., \& Levine, B. (2015). Severely deficient autobiographical memory (SDAM) in healthy adults: A new mnemonic syndrome. Neuropsychologia, 72, 105-118. doi: 10.1016/j.neuropsychologia.2015.04.012

Panoz-Brown, D., Corbin, H. E., Dalecki, S. J., Gentry, M., Brotheridge, S., Sluka, C. M., ... Crystal, J. D. (2016). Rats remember items in context using episodic memory. Current Biology, 26, 2821-2826. doi: 10.1016/j.cub.2016.08.023

Panoz-Brown, D., Iyer, V., Carey, L. M., Sluka, C. M., Rajic, G., Kestenman, J., ... Crystal, J. D. (2018). Replay of episodic memories in the rat. Current Biology, 28, 1628-1634.e7. doi: 10.1016/j.cub.2018.04.006

Perry, C. J., Barron, A. B., \& Chittka, L. (2017). The frontiers of insect cognition. Current Opinion in Behavioral Sciences, 16, 111-118. doi: 10.1016/j.cobeha.2017.05.011

Qadri, M. A. J., Leonard, K., Cook, R. G., \& Kelly, D. M. (2018). Examination of long-term visual memorization capacity in the clark's nutcracker (Nucifraga columbiana). Psychonomic Bulletin \& Review, 25, 2274-2280. doi: 10.3758/s13423-0181439-4

Ranganath, C., Yonelinas, A. P., Cohen, M. X., Dy, C. J., Tom, S. M., \& D'Esposito, M. (2003). Dissociable correlates of recollection and familiarity within the medial temporal lobes. Neuropsychologia, 42, 2-13. doi: 10.1016/j.neuropsychologia.2003.07.006

Redish, A. D. (2016). Vicarious trial and error. Nature Reviews Neuroscience, 17, 147-159. doi: 10.1038/nrn.2015.30

Renoult, L., Irish, M., Moscovitch, M., \& Rugg, M. D. (2019). From knowing to remembering: The semantic-episodic distinction. Trends in Cognitive Sciences, 23, 1041-1057. doi: 10.1016/j.tics.2019.09.008

Richardson-Klavehn, A., \& Bjork, R. A. (1988). Measures of memory. Annual Review of Psychology, 39, 475-543. doi: 10.1146/annurev.ps.39.020188.002355

Roberts, W. A. (2002). Are animals stuck in time? Psychological Bulletin, 128, 473-489. doi: 10.1037/00332909.128.3.473

Saive, A.-L., Royet, J.-P., Garcia, S., Thévenet, M., \& Plailly, 
J. (2015). "What-where-which" episodic retrieval requires conscious recollection and is promoted by semantic knowledge. PLOS ONE, 10, e0143767. doi: 10.1371/journal.pone.0143767

Schacter, D. L. (2001). Forgotten ideas, neglected pioneers: Richard Semon and the story of memory. Psychology Press. doi: 10.4324/9780203720134

Schacter, D. L., Eich, J. E., \& Tulving, E. (1978). Richard Semon's theory of memory. Journal of Verbal Learning and Verbal Behavior, 17, 721-743. doi: 10.1016/s00225371(78)90443-7

Schacter, D. L., Israel, L., \& Racine, C. (1999). Suppressing false recognition in younger and older adults: The distinctiveness heuristic. Journal of Memory and Language, 40, 124. doi: 10.1006/jmla.1998.2611

Schmidt, S. R. (1991). Can we have a distinctive theory of memory? Memory \& Cognition, 19, 523-542. doi: 10.3758/bf03197149

Schwartz, B. L., \& Evans, S. (2001). Episodic memory in primates. American Journal of Primatology, 55, 71-85. doi: 10.1002/ajp.1041

Schwartz, B. L., Hoffman, M. L., \& Evans, S. (2005). Episodic-like memory in a gorilla: A review and new findings. Learning and Motivation, 36, 226-244. doi: 10.1016/j.lmot.2005.02.012

Segundo-Ortin, M., \& Calvo, P. (2019). Are plants cognitive? a reply to adams. Studies in History and Philosophy of Science Part A, 73, 64-71. doi: 10.1016/j.shpsa.2018.12.001

Semon, R. (1921). The mneme. George Allen \& Unwin.

Sherry, D. F., Vaccarino, A. L., Buckenham, K., \& Herz, R. S. (1989). The hippocampal complex of food-storing birds. Brain, Behavior and Evolution, 34, 308-317. doi: 10.1159/000116516

Skov-Rackette, S. I., Miller, N. Y., \& Shettleworth, S. J. (2006). What-where-when memory in pigeons. Journal of Experimental Psychology: Animal Behavior Processes, 32, 345-358. doi: 10.1037/0097-7403.32.4.345

Sluka, C. M., Stanko, K., Campbell, A., Cáceres, J., PanozBrown, D., Wheeler, A., ... Allen, C. (2018). Incidental spatial memory in the domestic dog (Canis familiaris). Learning \& Behavior, 46, 513-521. doi: 10.3758/s13420-0180327-0

Small, S. A. (2002). The longitudinal axis of the hippocampal formation: Its anatomy, circuitry, and role in cognitive function. Reviews in the Neurosciences, 13. doi: 10.1515/revneuro.2002.13.2.183

Stark, S. M., Kirwan, C. B., \& Stark, C. E. L. (2019). Mnemonic similarity task: A tool for assessing hippocampal integrity. Trends in Cognitive Sciences, 23, 938-951. doi: 10.1016/j.tics.2019.08.003

Stark, S. M., Yassa, M. A., Lacy, J. W., \& Stark, C. E. L. (2013). A task to assess behavioral pattern separation (BPS) in humans: Data from healthy aging and mild cognitive impairment. Neuropsychologia, 51, 2442-2449. doi: 10.1016/j.neuropsychologia.2012.12.014

Strange, B. A., Witter, M. P., Lein, E. S., \& Moser, E. I. (2014). Functional organization of the hippocampal longitudinal axis. Nature Reviews Neuroscience, 15, 655-669. doi: $10.1038 /$ nrn3785

Suddendorf, T., \& Busby, J. (2003). Mental time travel in animals? Trends in Cognitive Sciences, 7, 391-396. doi: 10.1016/s1364-6613(03)00187-6

Suddendorf, T., \& Corballis, M. C. (2007). The evolution of foresight: What is mental time travel, and is it unique to humans? Behavioral and Brain Sciences, 30, 299-313. doi: 10.1017/s0140525x07001975

Taiz, L., Alkon, D., Draguhn, A., Murphy, A., Blatt, M., Hawes, C., ... Robinson, D. G. (2019). Plants neither possess nor require consciousness. Trends in Plant Science, 24, 677-687. doi: 10.1016/j.tplants.2019.05.008

Tolman, E. C. (1939). Prediction of vicarious trial and error by means of the schematic sowbug. Psychological Review, 46, 318-336. doi: 10.1037/h0057054

Tolman, E. C. (1948). Cognitive maps in rats and men. Psychological Review, 55, 189-208. doi: 10.1037/h0061626

Tulving, E. (1972). Episodic and semantic memory. In E. Tulving \& W. Donaldson (Eds.), Organization of memory (pp. 382-402). Academic Press.

Tulving, E. (1983). Elements of episodic memory. Oxford University Press.

Tulving, E. (1984). Précis of elements of episodic memory. Behavioral and Brain Sciences, 7, 223-238. doi: 10.1017/s0140525x0004440x

Tulving, E. (1985). Memory and consciousness. Canadian Psychology, 26, 1-12. doi: 10.1037/h0080017

Tulving, E. (2002). Episodic memory: From mind to brain Annual Review of Psychology, 53, 1-25. doi: 10.1146/annurev.psych.53.100901.135114

Tulving, E. (2005). Episodic memory and autonoesis Uniquely human? In H. S. Terrace \& J. Metcalfe (Eds.), The missing link in cognition: Origins of self-reflective consciousness (pp. 3-56). Oxford University Press. doi 10.1093/acprof:oso/9780195161564.003.0001

Tulving, E. (2016). Episodic memory. In R. J. Sternberg, S. T. Fiske, \& D. J. Foss (Eds.), Scientists making a difference (pp. 152-155). Cambridge University Press. doi: $10.1017 /$ cbo9781316422250.034

Turriziani, P., Fadda, L., Caltagirone, C., \& Carlesimo, G. A. (2004). Recognition memory for single items and for associations in amnesic patients. Neuropsychologia , 42, 426-433. doi: 10.1016/j.neuropsychologia.2003.10.003

Valenchon, M., Lévy, F., Górecka-Bruzda, A., Calandreau, L. \& Lansade, L. (2013). Characterization of long-term memory, resistance to extinction, and influence of temperament during two instrumental tasks in horses. Animal Cognition, 16, 1001-1006. doi: 10.1007/s10071-013-0648-5

Vann, S. D., Tsivilis, D., Denby, C. E., Quamme, J. R., Yonelinas, A. P., Aggleton, J. P., ... Mayes, A. R. (2009). Impaired recollection but spared familiarity in patients with extended hippocampal system damage revealed by 3 convergent methods. Proceedings of the National Academy of Sciences USA, 106, 5442-5447. doi: 10.1073/pnas.0812097106

Verfaellie, M., Koseff, P., \& Alexander, M. (2000). Acquisition of novel semantic information in amnesia: effects of lesion location. Neuropsychologia, 38, 484-492. doi: 10.1016/s0028-3932(99)00089-5 
Volman, S. F., Thomas C. Grubb, J., \& Schuett, K. C. (1997). Relative hippocampal volume in relation to food-storing behavior in four species of woodpeckers. Brain, Behavior and Evolution, 49, 110-120. doi: 10.1159/000112985

Wang, W.-C., Brashier, N. M., Wing, E. A., Marsh, E. J., \& Cabeza, R. (2018). Knowledge supports memory retrieval through familiarity, not recollection. Neuropsychologia, 113, 14-21. doi: 10.1016/j.neuropsychologia.2018.01.019

Weisberg, S. M., Newcombe, N. S., \& Chatterjee, A. (2019). Everyday taxi drivers: Do better navigators have larger hippocampi? Cortex, 115, 280-293. doi: 10.1016/j.cortex.2018.12.024

Whittlesea, B. W. A. (1993). Illusions of familiarity. Journal of Experimental Psychology: Learning, Memory, and Cognition, 19, 1235-1253. doi: 10.1037/0278-7393.19.6.1235

Yassa, M. A., \& Stark, C. E. (2011). Pattern separation in the hippocampus. Trends in Neurosciences, 34, 515-525. doi: 10.1016/j.tins.2011.06.006

Yonelinas, A. P. (2001). Components of episodic memory: the contribution of recollection and familiarity. Philosophical Transactions of the Royal Society of London. Series B: Biological Sciences, 356, 1363-1374. doi: 10.1098/rstb.2001.0939

Yonelinas, A. P. (2002). The nature of recollection and familiarity: A review of 30 years of research. Journal of Memory and Language, 46, 441-517. doi: 10.1006/jmla.2002.2864

Yonelinas, A. P., Kroll, N. E., Quamme, J. R., Lazzara, M. M., Sauvé, M.-J., Widaman, K. F., \& Knight, R. T. (2002). Effects of extensive temporal lobe damage or mild hypoxia on recollection and familiarity. Nature Neuroscience, 5, 1236-1241. doi: $10.1038 / \mathrm{nn} 961$

Zentall, T. R., Clement, T. S., Bhatt, R. S., \& Allen, J. (2001). Episodic-like memory in pigeons. Psychonomic Bulletin $\mathcal{E}$ Review, 8, 685-690. doi: 10.3758/bf03196204

Zentall, T. R., Singer, R. A., \& Stagner, J. P. (2008). Episodiclike memory: Pigeons can report location pecked when unexpectedly asked. Behavioural Processes, 79, 93-98. doi: 10.1016/j.beproc.2008.05.003

Zhou, W., \& Crystal, J. D. (2009). Evidence for remembering when events occurred in a rodent model of episodic memory. Proceedings of the National Academy of Sciences USA, 106, 9525-9529. doi: 10.1073/pnas.0904360106 